\title{
DISAPPEARING BONES
}

\section{S. M. Milner, Manchester, England, and S. L. Baker, Orford, Suffolk, England}

There does not appear to have been any report in this country of a case of disappearing bones on the scale here presented, though a number of cases have been reported in the United States of America and on the Continent. The patient is an elderly woman in whom the bones of the left upper limb have been progressively disappearing.

Seemingly the first report of a case of this kind appeared in the Boston Medical and Surgical Journal in 1872, entitled " Absorption of the humerus after fracture "- the implications being that the fracture was the starting point of the condition. Possibly this is putting the cart before the horse.

Another case was reported by Branch in 1945, and a review of cases of vanishing bones was made by Gorham and Stout in 1955. They appended a bibliography of thirty-five items, and suggested that the "progressive osteolysis is always associated with an angiomatosis of blood and sometimes lymphatic vessels, which seemingly are responsible for it."

\section{CASE REPORT}

A single woman, born in 1887, complained of pain and incapacity in the left shoulder. She worked in a cotton mill until July 1947 when she gave up work to nurse a sick mother. She had enjoyed good health, but in 1941 had had her uterus removed together with a para-ovarian fibroid weighing $8 \mathrm{lb}$.

In 1945 she tripped and fell rather heavily on her left shoulder and arm, bruising the outer side from mid-arm to mid-forearm, but she did not stay away from work.

In May 1945, when consulting her doctor about cystitis, she complained of pain and stiffness in her left shoulder. Radiographs of the left shoulder showed an apparently normal humerus and ribs, but the whole of the clavicle and scapula presented irregular areas of absorption without any evidence of bone reaction (Fig. 1). She received a course of radiant heat and massage, with some improvement in the shoulder stiffness. No further notice was taken until two years later-December 1948-when radiographs to include the chest and both shoulders displayed the ribs still looking normal; but the humerus now showed gross rarefaction and all that remained of the clavicle and scapula was a bit of the lower part of each in the neighbourhood of the shoulder joint (Fig. 2). Seen a month later (January 1949) she complained of pain over the outer side of the left arm, the top of the shoulder and the scapular region, somewhat relieved by kaolin poultices. She had lost over a stone $(14 \mathrm{lb} .=6$ kilograms $)$ in weight in two years.

Examination-She had only a few degrees of movement in the left shoulder. She could get her left hand on to her right shoulder but little else. Movements in all the more distal joints were good.

The shoulder as a whole drooped, the thoracic cage giving a prominence in the midtrapezius line, but there was no tumour mass. There was a nodule, about half an inch in diameter, in the right lobe of the thyroid gland.

Investigations-Haemoglobin 98 per cent. Red blood corpuscles 5,330,000 per cubic millimetre. Colour index 0.92 . Mean diameter $6.5 \mu$. White blood cells 5,300 per cubic millimetre (neutrophils 77.0 per cent; eosinophils 0.5 per cent; basophils 0.5 per cent; lymphocytes 17.0 per cent; monocytes 5.0 per cent). Inorganic phosphorus 3.8 milligrams per 100 millilitres serum (repeat 3.5). Alkaline phosphatase 21.5 units (repeat 25.5). Calcium 12.2 milligrams per 100 millilitres serum (repeat 11.0). Wassermann reaction negative. Serum proteins: albumin 4.0 per cent; globulin 4.2 per cent; total 8.2 per cent. Albumin/globulin ratio 0.96. 


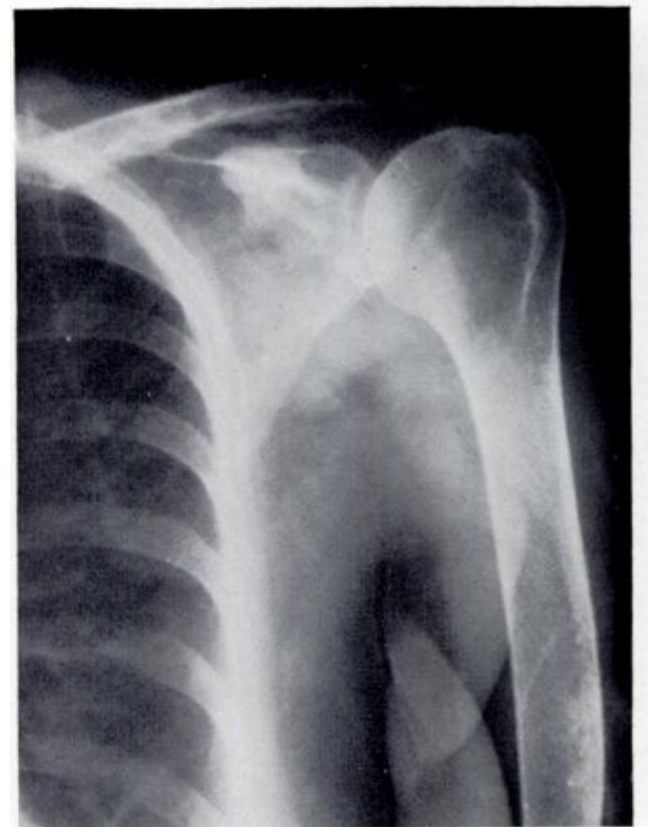

Fig. 1

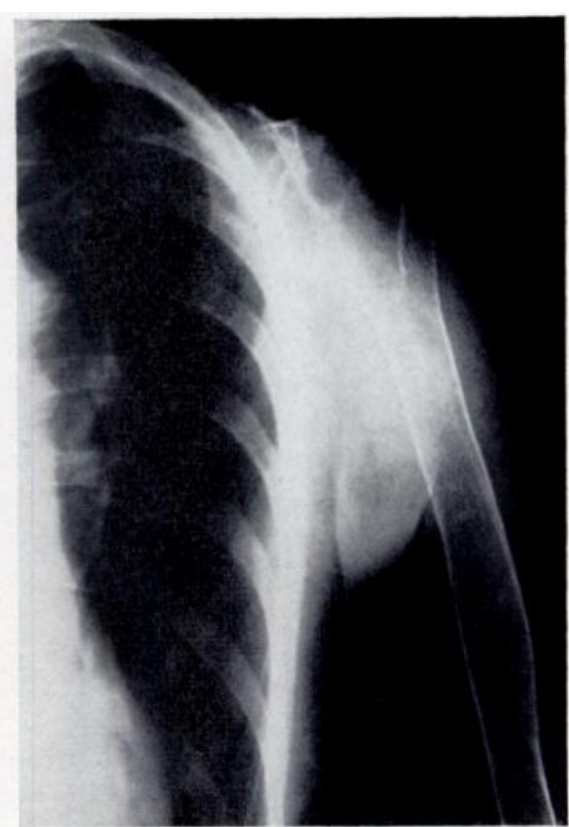

FIG. 2

Figure 1-Initial radiograph, showing early involvement of the clavicle and scapula. Figure 2-Two years later. The clavicle has disappeared. Of the scapula, only the glenoid remains. Absorption of the humerus is well advanced.

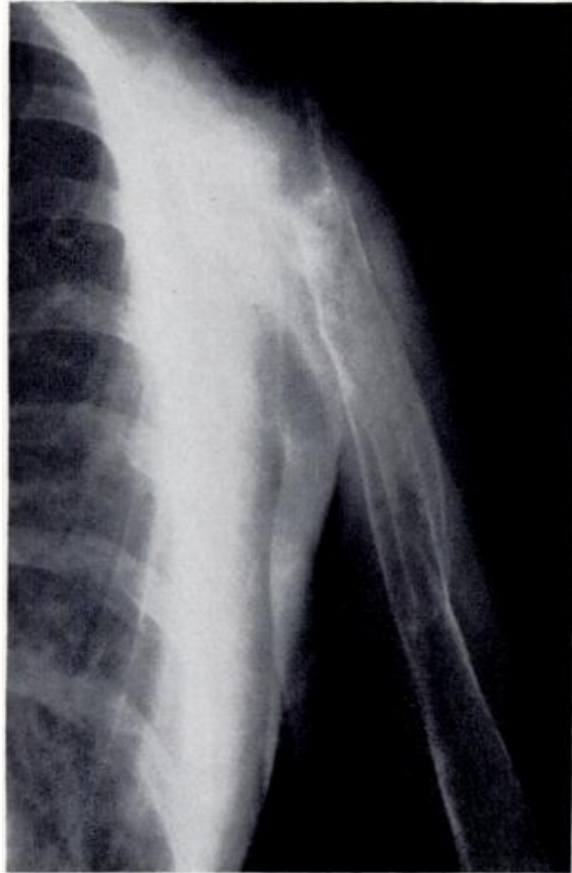

Fig. 3

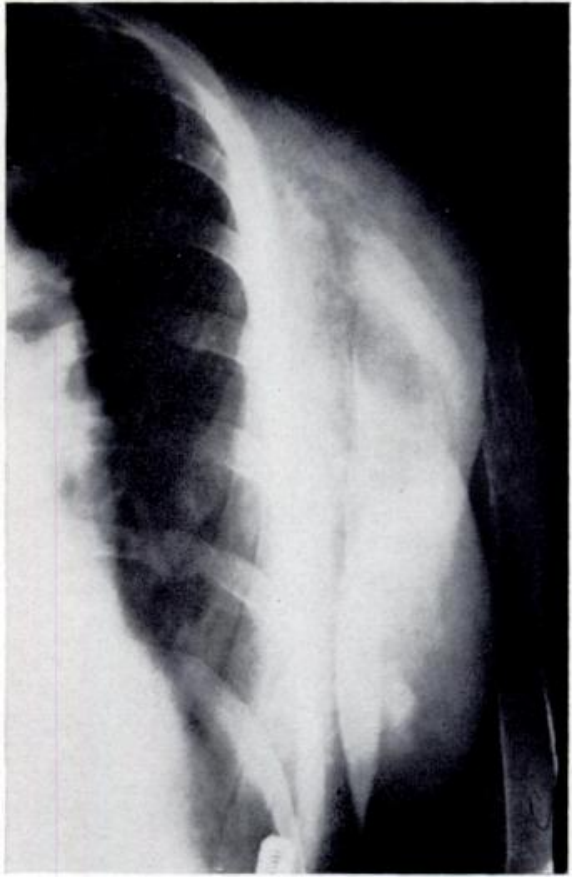

Fig. 4

Figure 3-Three and a half years after onset. The humeral head is merely a ghost. The spontaneous fracture of the surgical neck can be seen. Figure 4-Five years after onset. The upper half of the humerus has gone. 
Stools-Total fat 35.3 per cent of dried faeces; split fat 87 per cent of total fat; unsplit fat 13 per cent of total fat. (These results indicated defective fat absorption with normal fat splitting.) Control radiograph-A radiograph of one leg taken synchronously on the same film with the leg of another out-patient of like sex, age and build showed almost equal density in the tibiae of patient and control.

Arteriographs (Fig. 8) did not show any opacity such as might be expected with a haemangioma. Biopsy-This was carried out in February 1949, through an anterior incision. It was difficult to recognise the anatomy, because the only bony point to be felt above the humerus was the

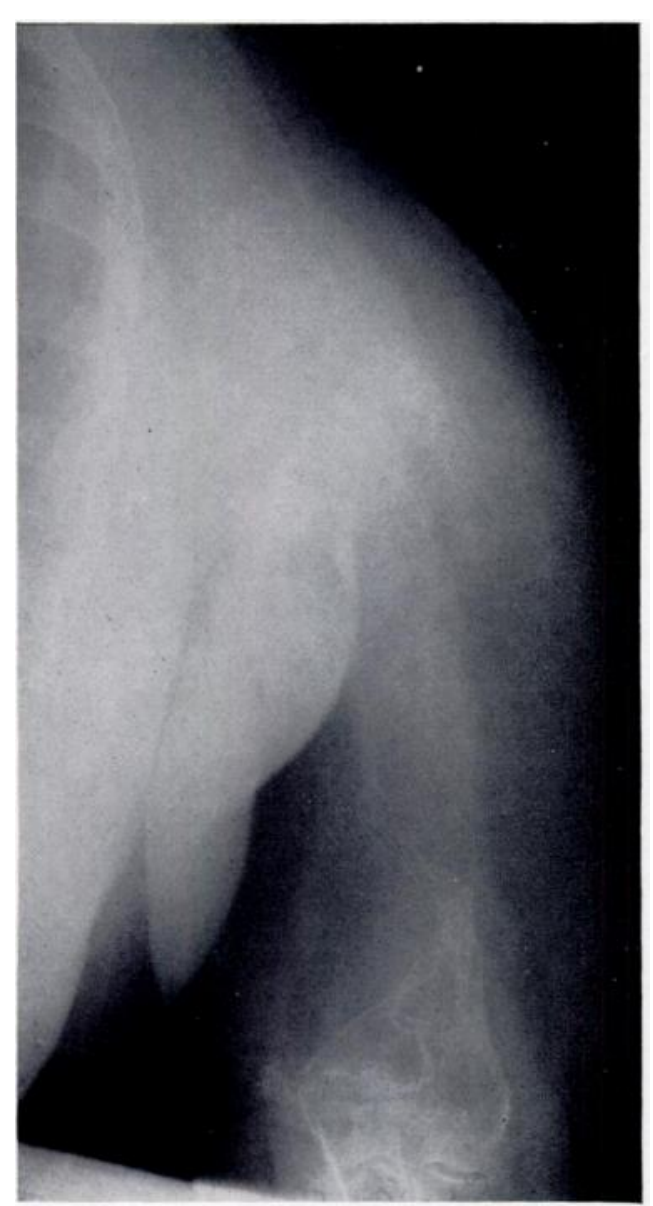

FIG. 5

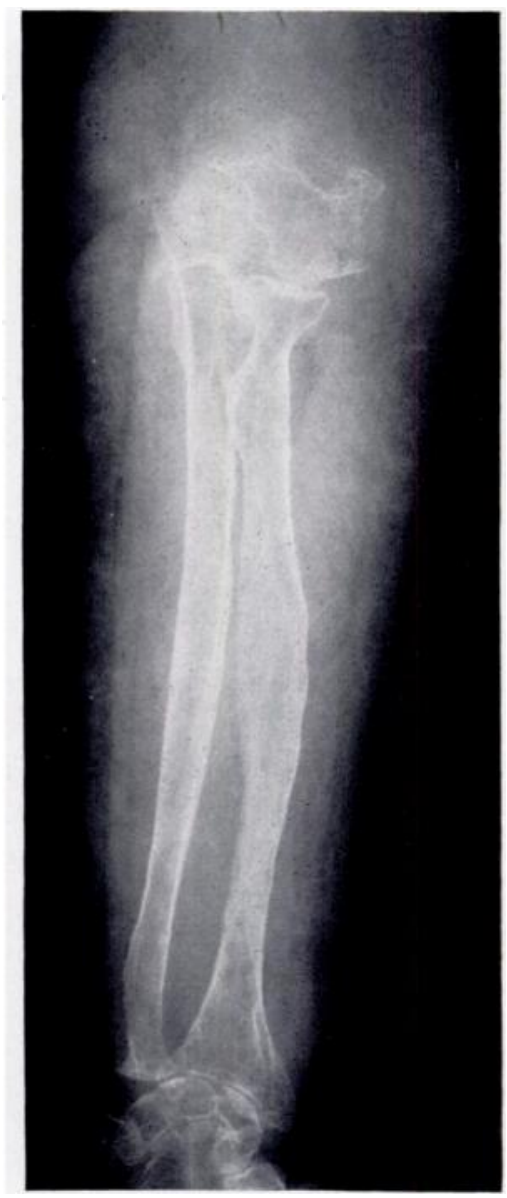

FiG. 6

Figure 5-Eight years after onset. Only the lower end of the humerus remains. Figure 6-Ten years after onset. Further absorption of humerus, radius and ulna. To a less extent the hand was also affected.

anterior edge of the glenoid. The muscles arising from the coracoid process were traced upwards and found to be attached to a tiny fragment of bone having tenuous connections up into the neck. A finger put round the margin of the glenoid encountered a rough, rather sandpapery surface immediately behind the glenoid proper. The glenoid was removed by cutting round the capsule. This was sent for section. The remains of the coracoid were taken out, and the muscles were sewn to the remainder of the capsule around the head of the humerus. Progress-In February 1950 the patient had increasing pain below the shoulder and she could not use the arm. Seen a week later, she presented a good deal of swelling around the lower 
half of the humerus, and crepitus in the upper part of the shaft. Radiographs showed extreme rarefaction throughout the whole humerus; and there was a crack about an inch below the surgical neck, without displacement (Fig. 3). She was treated symptomatically with a light plaster slab.

In April 1950 the neck was explored by Professor John Morley, who removed the enlarged right thyroid lobe and a thyroid adenoma from the isthmus. The parathyroid glands were not seen. In the next year she gained $2 \frac{1}{2}$ stone ( $35 \mathrm{lb} .=16$ kilograms).

In May 1952 the upper end of the humerus had disappeared and there was nothing to be felt above its lowest third (Fig. 4). The whole arm was flail above the elbow. Further

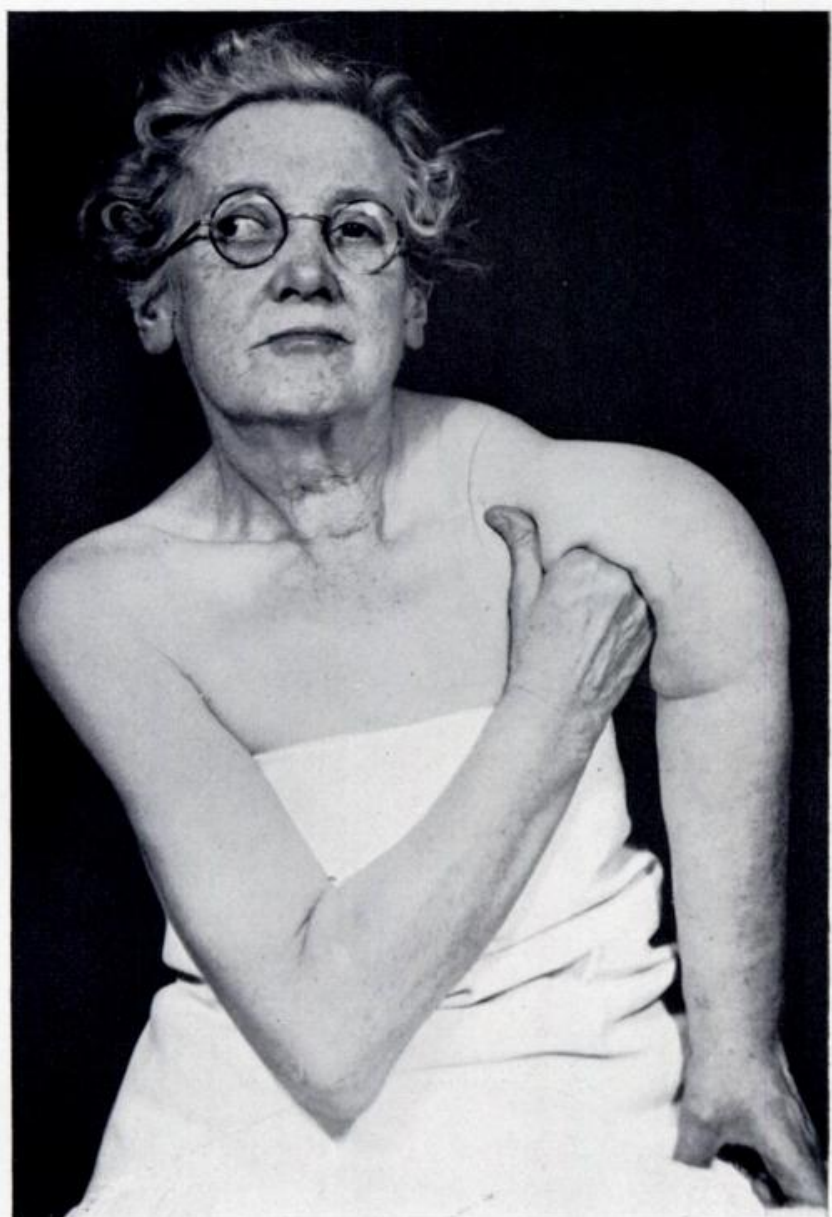

FiG. 7

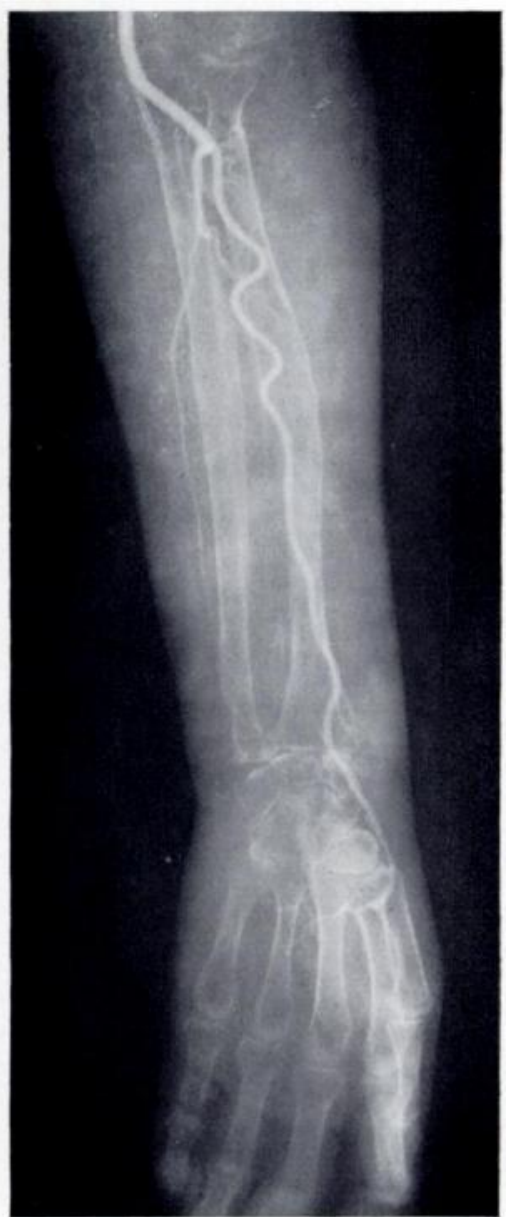

FIG. 8

Figure 7-Photograph of the patient, illustrating the flexibility of the humerus. Figure 8-Arteriograph (1958): no evidence of haemangioma.

radiographs taken in 1954 and 1957 are shown in Figures 5 and 6, and a clinical photograph is shown in Figure 7. The upper arm has become completely flexible and can be bent and twisted in any direction, so that the forearm can be made to assume all kinds of abnormal positions. The epicondyles can still be felt, and the ribs can be palpated in the upper part of the thoracic wall which normally lies under the scapula. The patient is free from pain. She has control of wrist and finger movements although she has nothing like normal power. Her general health remains good. She lives alone and does her own housework although she is now seventy. We have not been able to find evidence of bone disappearance in any other part of the skeleton.

VOL. 40 B, NO. 3, AUGUST 1958 


\section{PATHOLOGY}

Pathology of biopsy specimen-The specimen consisted of part of the cartilaginous surface of the glenoid cavity with what little remained of the supporting bone. The sections showed extreme bone atrophy with small areas of active osteoclasis and numerous dilated thin-walled vessels. There was no evidence of tumour.

In the absence of any neoplastic or other evident cause of the bone absorption the case remained a mystery until reference to Coley's (1949) remarks on "Phantom Bone" revealed its identity.

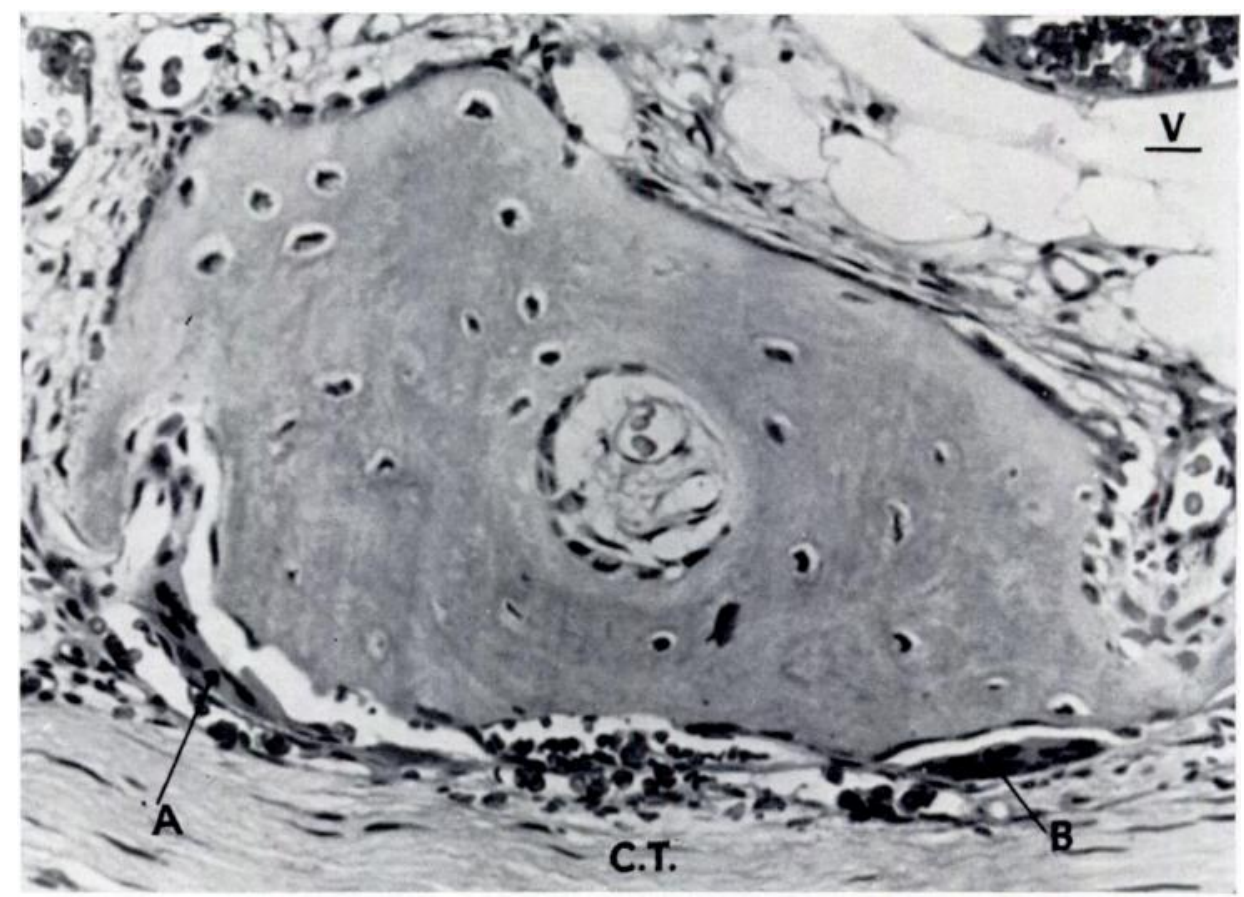

FiG. 9

Field from the deep surface of the cancellous bone below which is a connective-tissue layer (C.T.). The lower border of the bone shows an irregular surface; between this and the connective tissue is a narrow gap containing two elongated osteoclasts ( $\mathrm{A}$ and $\mathrm{B}$ ) and a few red cells. The osteoclasts have been pulled away from the bone by shrinkage of the section; A has a very irregular surface corresponding approximately with the irregularities of the bone surface. Part of a blood-filled thin-walled vessel (V) is seen in the fatty marrow (top right). (Paraffin section; haematoxylin and eosin, 315.)

Re-examination of the slides (1957) - As the patient had now been under observation for over ten years and Gorham and Stout's (1955) most useful paper on the histology of the condition had appeared, the sections were further studied.

Gorham and Stout found in sections obtained from eight of twenty-four cases an essentially similar histological picture, the most striking feature being the greatly enlarged thin-walled vessels in the marrow spaces of the affected bone. These were mostly distended with red cells, but some, particularly those in the connective tissue remaining after absorption of the bone, formed an anastomosing system of empty vascular spaces. Gorham and Stout called the condition " haemangiomatosis," but noted that the process did not resemble the formation of ordinary haemangiomata in bones. The mechanism by which the bony trabeculae were absorbed was not apparent, no osteoclasts being recognised.

The sections from the 1949 biopsy of the present case show the intact hyaline cartilage of the glenoid cavity with a thin layer of supporting cancellous bone which is about six millimetres 


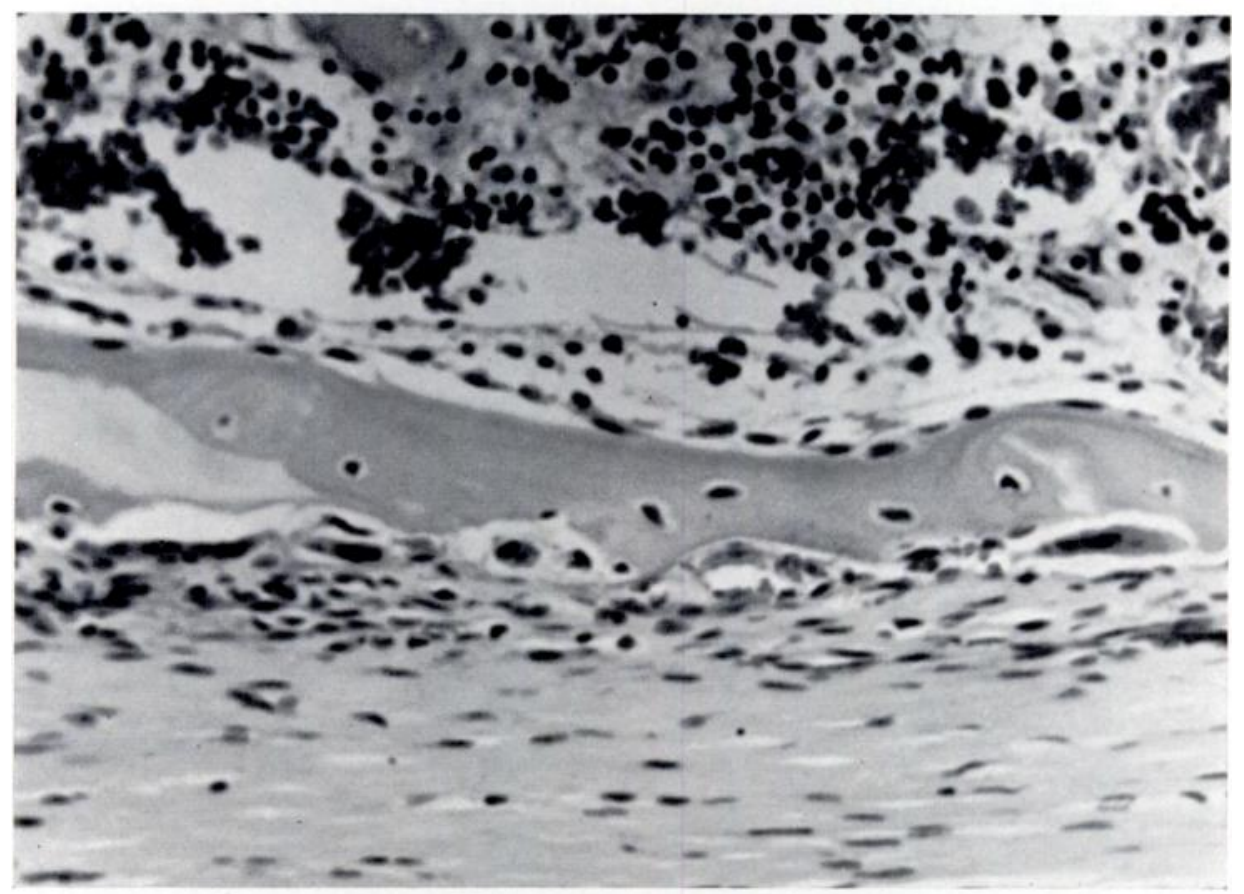

FiG. 10

Normal bone absorption on inner surface of infant's rib, for comparison with Figure 9 . Periosteum below; above this a trabecula of bone showing subperiosteal osteoclastic absorption with shallow bays (Howship's lacunae) produced by flattened osteoclasts. A line of these cells (pulled away from the bone by shrinkage) lies between the bone and the periosteum. (Paraffin section; haematoxylin and eosin, $\times 315$.)

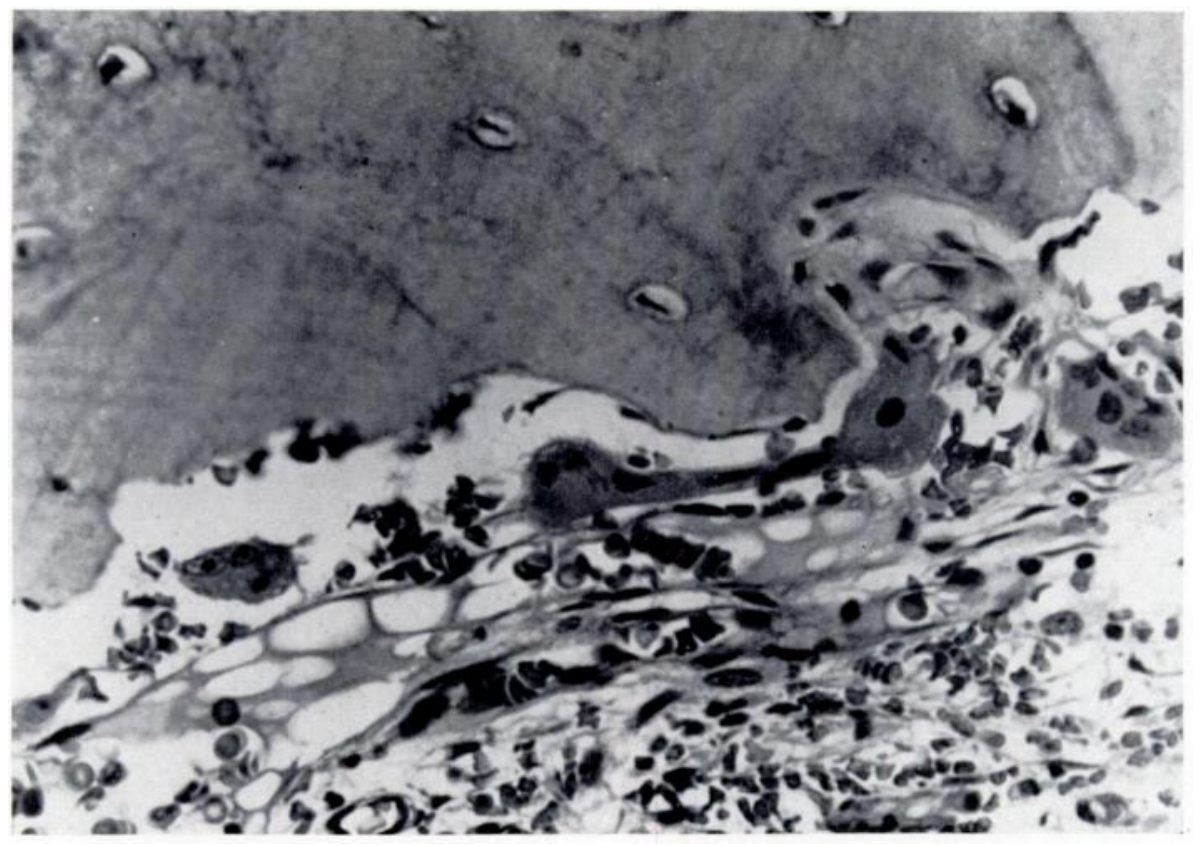

FIG. 11

Another field near that shown in Figure 9; a relatively large dumb-bell-shaped osteoclast and two smaller specimens are seen. The bone surface shows many shallow erosion pits (Howship's lacunae). Below is vascular reticular tissue with some haemorrhage. (Paraffin section: haematoxylin and eosin, $\times 500$.) 
thick at one end of the section but tails off at the other end, where only a few minute fragments of bone remain at the base of the cartilage. The spaces in this cancellous bone are filled by fatty marrow containing many relatively large thin-walled vessels distended by red blood cells (Fig. 13). Over most of its free surface (except at one end where the soft tissues have become detached and only a little haemorrhage remains) a thin layer of connective tissue covers the bone, separating it from a little underlying fat and muscle. The trabeculae of the cancellous bone, where they abut on the connective tissue layer, show irregular pitted surfaces, and numbers of osteoclasts, mostly of the flat type, can be seen on, or slightly separated from,

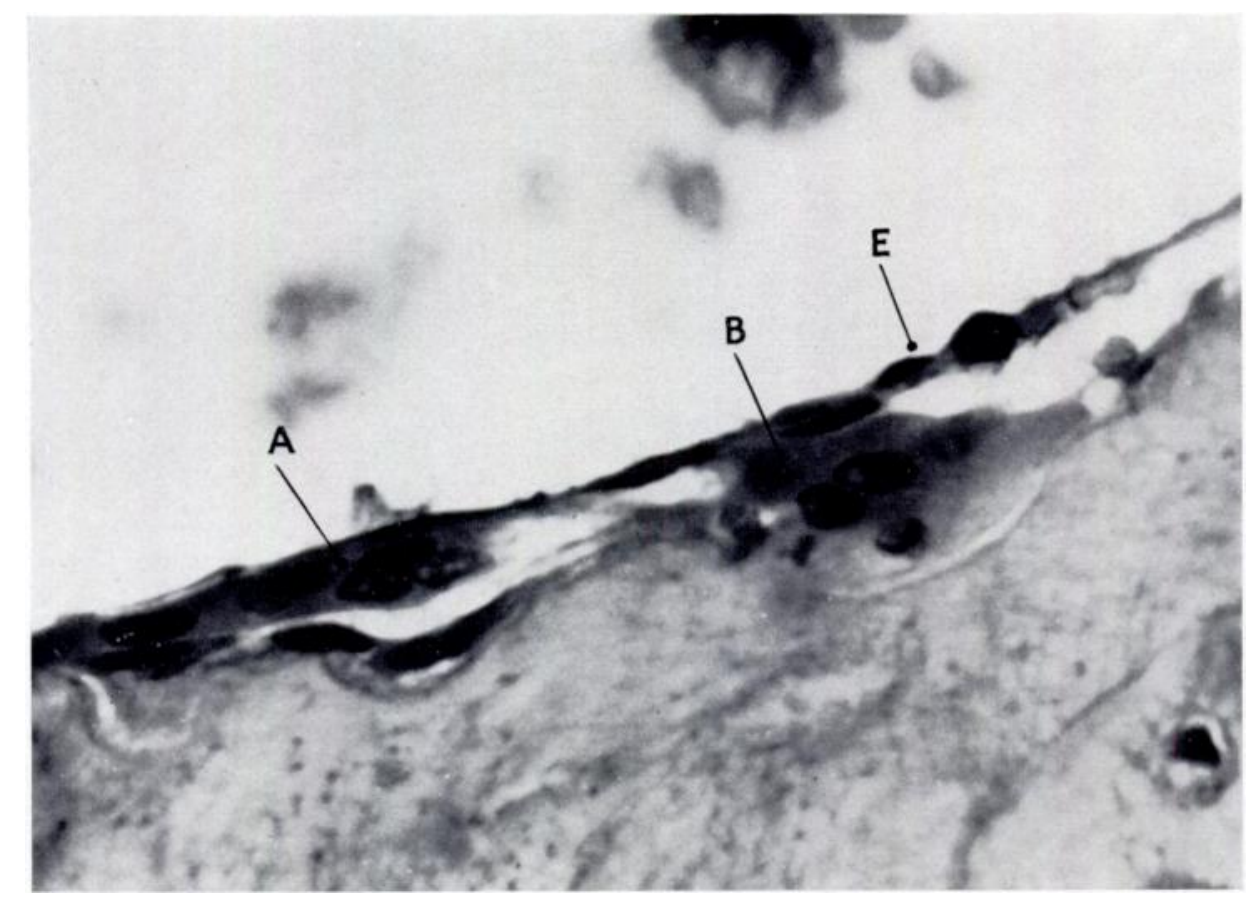

Fig. 12

Osteoclasts lying between wall of a venous sinusoid and the bone surface. Running diagonally across the picture is the endothelial wall of the sinusoid $(\mathrm{E})$; above this is part of its lumen with some scattered clumps of red cells (out of focus). Lying between the endothelium and the bone are two osteoclasts (A and B). The spindle-shaped specimen (A) was inactive at the time of biopsy since it is separated from the bone by three osteoblasts (which are probably starting to fill in the two small pits which they cover). The more rounded osteoclast (B) is active and has produced an erosion pit in which it is partly embedded. (Paraffin section; haematoxylin and eosin, $\times 950$.)

the pitted bone surfaces (Figs. 9, 11 and 12). Numerous distended thin-walled vessels-some containing red cells, others empty-are seen in this connective tissue layer. Neither the underlying muscle nor the fatty tissue on its surface shows signs of increased vascularity. At one point a relatively large very thin-walled vessel or sinus, partly filled with red cells, lies on the surface of the connective tissue layer and in contact with a trabecula, whose adjacent surface shows many shallow pits occupied by osteoclasts, mostly small and flattened, lying between the sinus wall and the bone surface (Fig. 12).

Osteoclasts were found only in relation to those parts of trabeculae that abutted on the connective tissue layer and showed lacunar absorption of their surfaces; none was found on the surfaces of the trabeculae in the vascular fatty marrow, nor did these trabeculae show any lacunar absorption.

Except for a few small trabeculae of imperfectly lamellar bone there was no sign of new bone formation. 


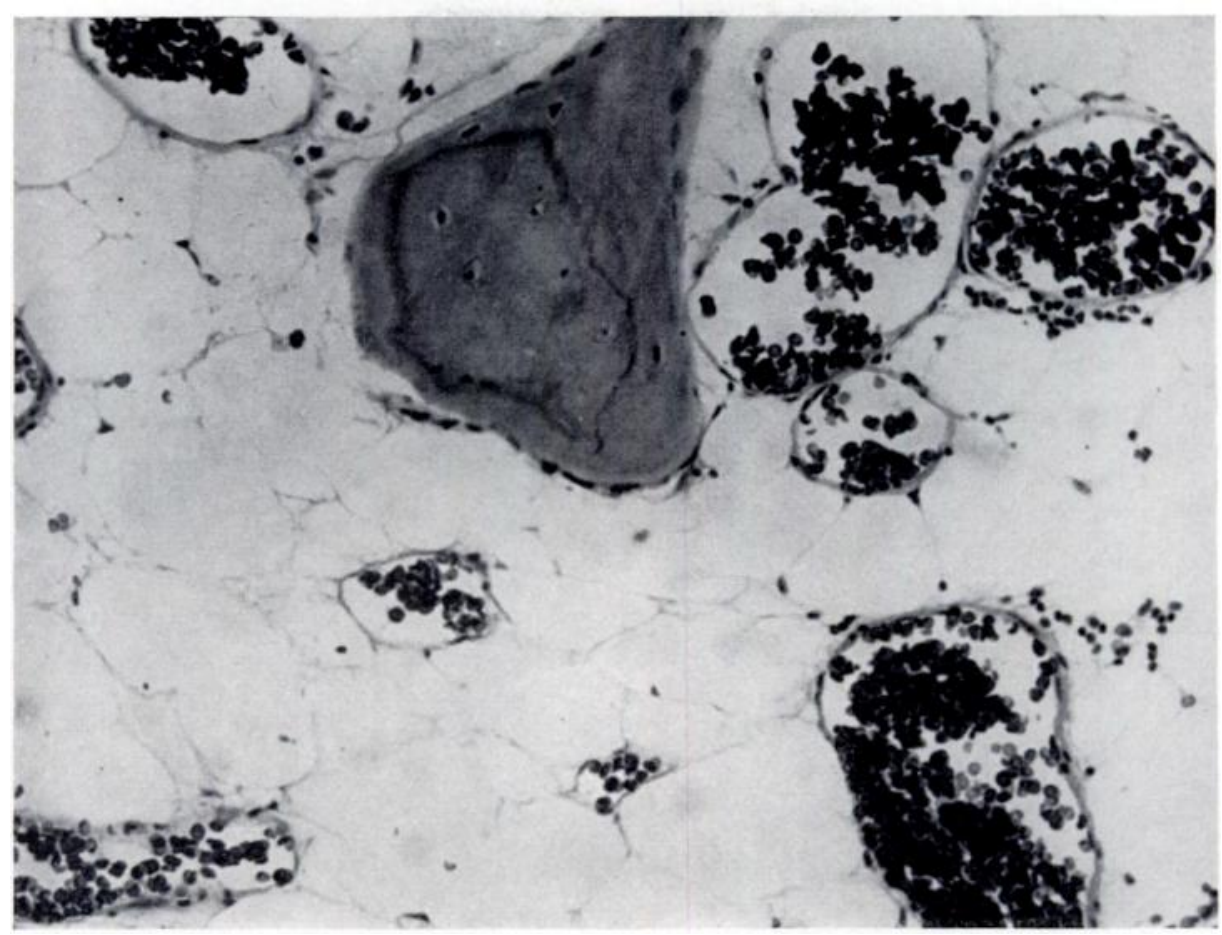

FIG. 13

Enlarged venous capillaries in fatty marrow from cancellous bone in biopsy from this case. (Paraffin section; haematoxylin and eosin, $\times 200$.)

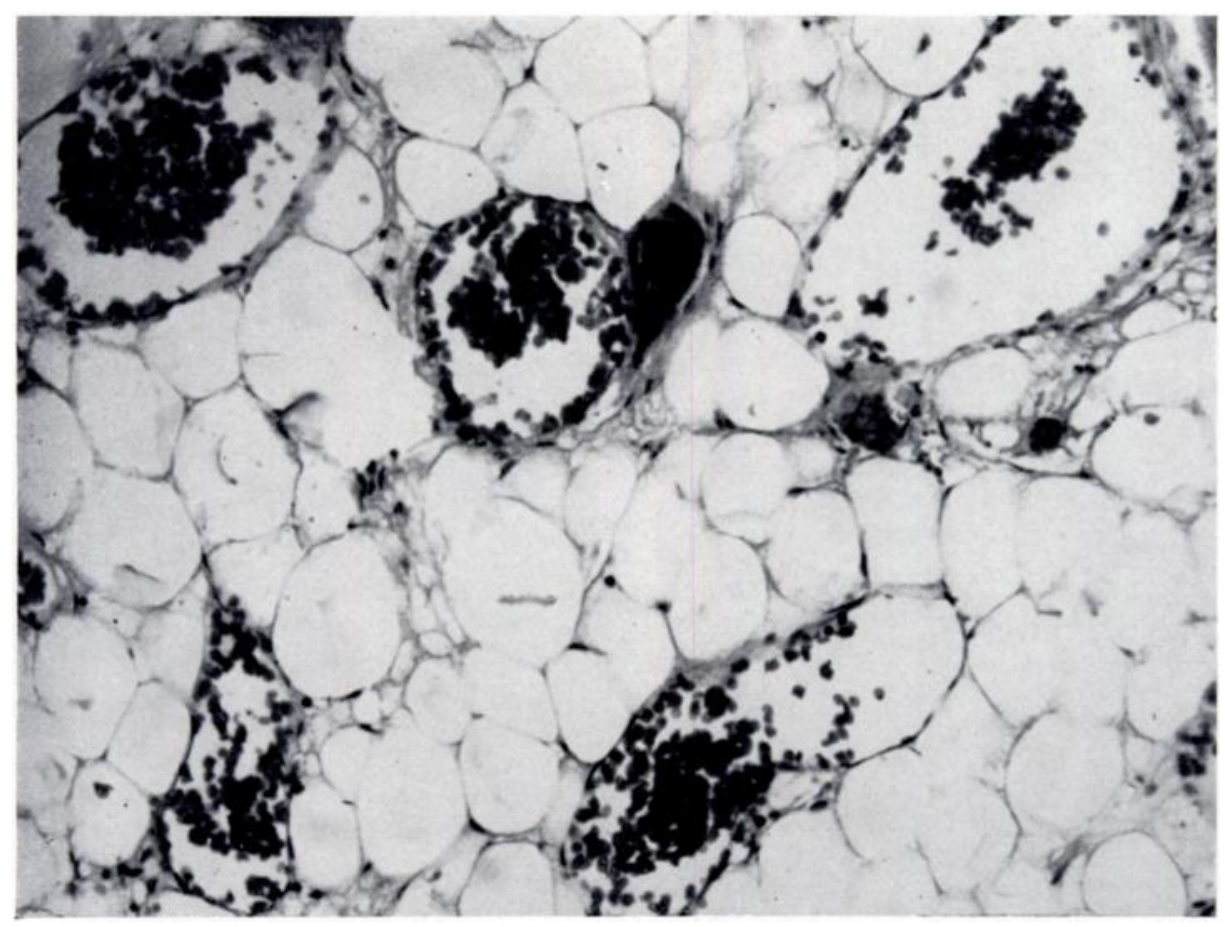

FIG. 14

Biopsy from line of healing four weeks after compression arthrodesis of knee. Venous capillaries similar to those in Figure 13 in fatty marrow of femur near line of healing. (Paraffin section; haematoxylin and eosin, $\times 200$.)

vol. $40 \mathrm{~B}$, No. 3, AUGUST 1958 


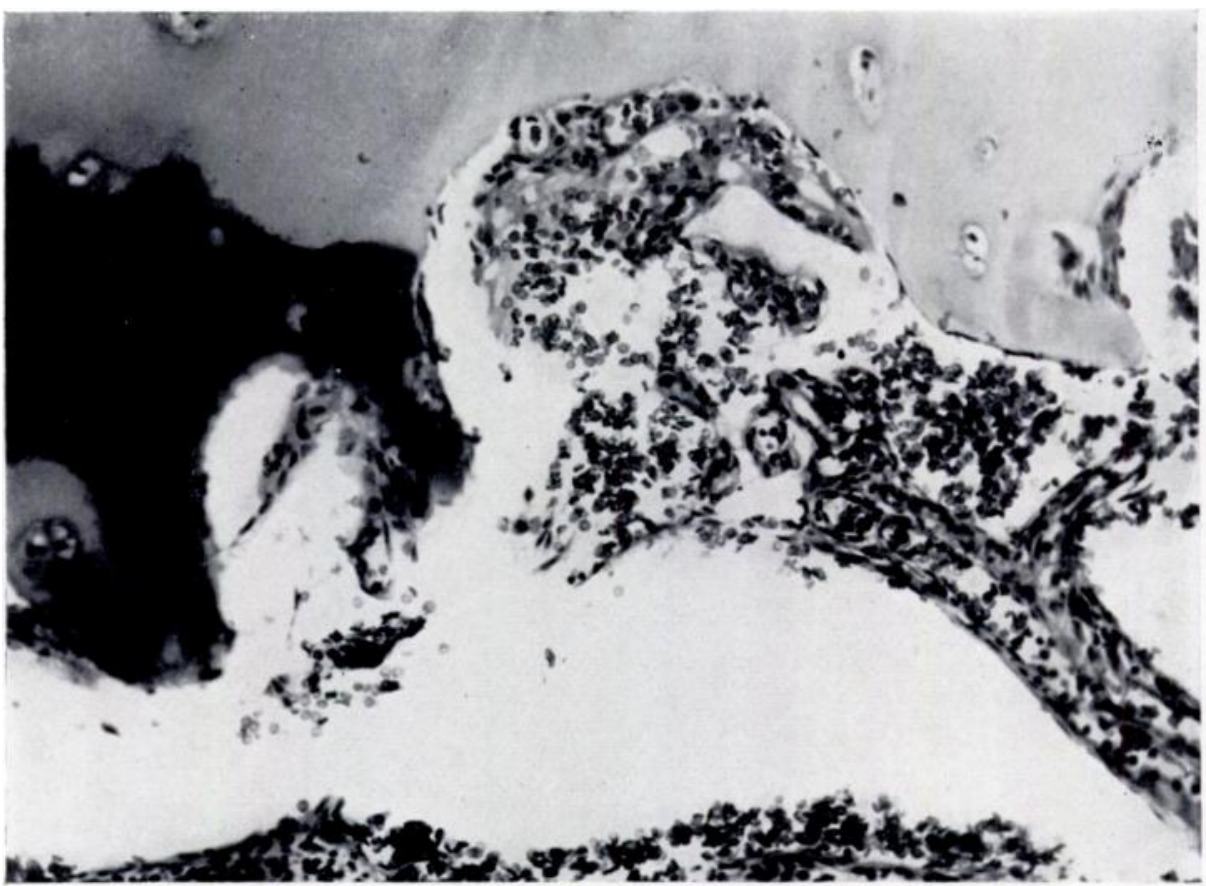

FIG. 15

A small focus of vascular absorption in the base of the articular cartilage of the glenoid cavity. A vascular tuft is seen extending into a bay in the non-calcified hyaline cartilage with its capillary loops in contact with the cartilage surface. To the left is the remains of the zone of calcified cartilage (dark zone). The underlying bone has been absorbed. (Paraffin section; haematoxylin and eosin, 200.)

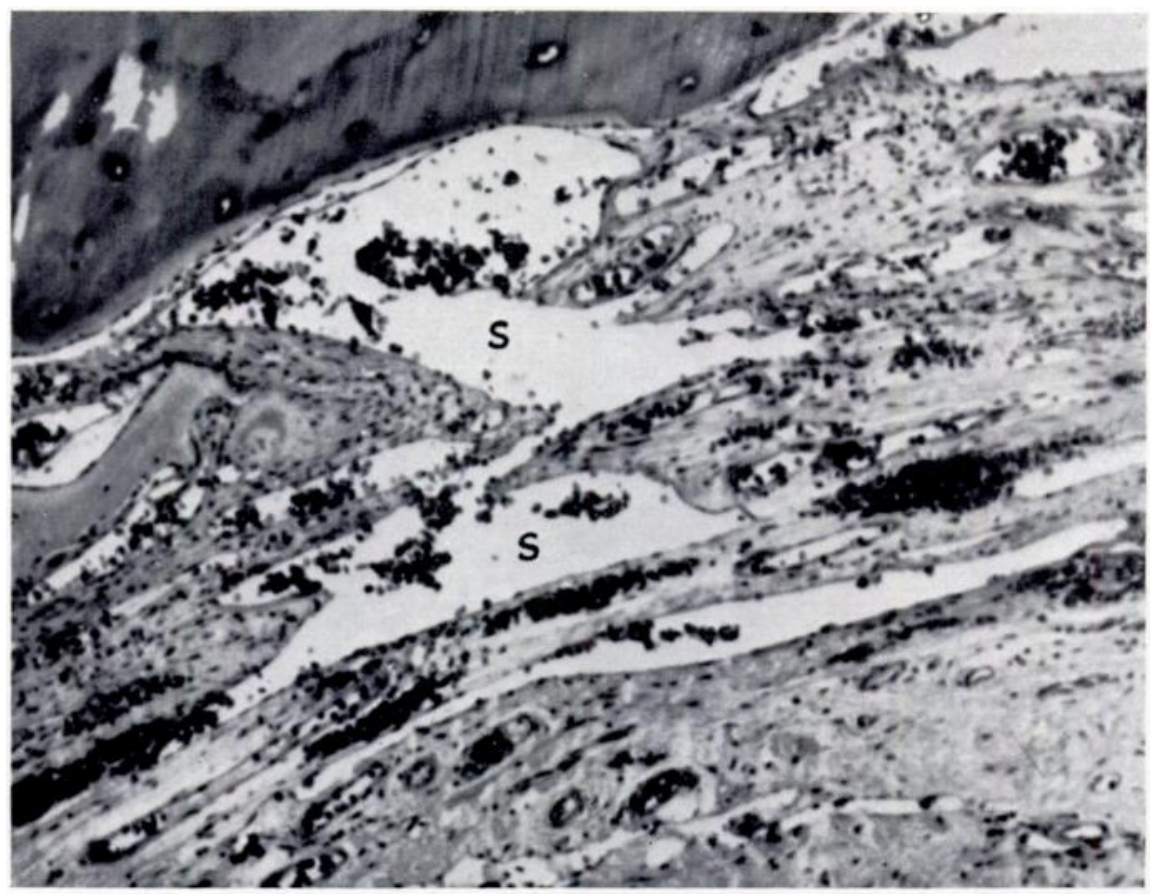

FiG. 16

Thin-walled intercommunicating sinusoids $(\mathrm{S}, \mathrm{S})$ in the connective tissue at the base of the cartilage at a site where nearly all the bone has been absorbed. The sinusoids contain scattered groups of red cells; smaller vessels extend from them running parallel to the connective tissue bundles on either side. (Paraffin section; haematoxylin and eosin, $\times 140$.) 
Where the supporting bone at its base had been largely removed, cartilage was being absorbed at a few points. Figure 15 shows a small vascular tuft which passes through a gap in the calcified zone at the base of the cartilage and is producing absorption of the non-calcified cartilage.

Calcified cartilage, like bone, is commonly absorbed by osteoclasts, but it is generally accepted that non-calcified cartilage can be removed without the development of multinucleated cells-apparently by masses of small cells (possibly endothelial) at the surface of the vascular buds-a process of vascular absorption.

In some places from which the bone at the base of the articular cartilage had disappeared, leaving only connective tissue bundles, the intervening spaces are filled by intercommunicating vascular spaces (" sinusoids"), walled by only a single layer of endothelium. Some contained clumps of red cells; others were almost empty (Fig. 16).

\section{DISCUSSION}

Bone absorption-The appearances in our sections correspond in general with those described by Gorham and Stout (1955) but with one important difference: Gorham and Stout found no osteoclasts or any other indication of the mechanism of bone absorption, whereas in our material osteoclasts and Howship's lacunae were present in the deep surface of what remained of the cancellous bone. The appearances here were very like those seen in the normal remodelling of infants' bones, particularly in the areas of active surface absorption such as occur on the pleural surface of the ribs in the metaphysial region (Fig. 10); there is a continuous subperiosteal osteoclastic absorption on the inner (concave) surface while new periosteal bone is being deposited on the outer (convex) surface of the rib.

The pathological absorption in our material appeared rather more active than the normal surface absorption at the most active sites in the ribs of infants a few weeks old, as witness 1) more numerous osteoclasts (ten osteoclasts on a 1.5 millimetre length of bone surface against five on the same length of normal infant's bone) and 2) on the average rather larger osteoclasts (Fig. 11).

There is (Kölliker 1873) a correlation between the size of the osteoclasts and the rate of bone absorption. Where this is rapid the osteoclasts are large and produce deep pits (Howship's lacunae); where it is slow, small flattened osteoclasts produce much less conspicuous shallow pits. Normal osteoclasis in post-natal life is slow as compared with most forms of pathological osteoclasis. The rapid osteoclasis in Paget's osteitis fibrosa, for instance, shows numerous very large osteoclasts and correspondingly large erosion pits. In this case of disappearing bones the histology is not that of a rapid pathological absorption, but indicates a rate of absorption not greatly exceeding that in the normal remodelling process in young children. The synonym "acute spontaneous absorption of bone" is not really appropriate, because in most cases it takes years to absorb a limb bone-in this case approximately eight years to absorb the humerus. This rate of absorption could be compensated for by a moderate grade of osteoplastic activity, but there is little sign of any active new bone formation either histologically or radiographically - a point noted in Gorham and Stout's series of cases. The very poor osteoplastic activity in the affected bone seems to be an important part of the disease, and would account for the gradual removal of the affected bone with a persistent osteoclasis of only moderate activity. (As the condition advanced and the limb was put out of action, disuse also must have played a part in the atrophy.)

As already noted, in our slides osteoclastic absorption was confined to the exposed surface of the cancellous bone fragment, no osteoclasts or Howship's lacunae being found on trabeculae away from this surface.

Vascular changes-The large, thin-walled, distended vessels resembling those described and figured by Gorham and Stout (1955) were conspicuous in the fatty marrow of the cancellous bone in our biopsy material. These distended vessels, though much larger and more conspicuous, 
were not more numerous than the small capillaries in samples of normal fatty connective tissue and fatty bone marrow. The fatty connective tissue just outside the bone in our case (distant only a few millimetres from the congested bone marrow) showed only the usual fine capillaries, carrying as a rule only a single line of red cells. Counts of these capillaries showed that, though inconspicuous, they were more numerous than the distended vessels in the bone marrow. Enlargement of the normal capillaries would, therefore, be sufficient to produce the appearances seen in the marrow spaces.

The vessels that enlarge in this way are the venous capillaries which, though normally inconspicuous in fatty marrow, can increase in size under various conditions to form large thinwalled "sinusoids." Various types of cellular activity in the marrow will produce such an enlargement, which is a normal event when fatty marrow is replaced by the much more active haemopoietic marrow whose sinusoids have been studied by various workers (Maximow 1927). A simple reaction in bone is sufficient to enlarge the venous capillaries in the neighbouring fatty marrow to a degree comparable with that seen in these cases. One of us (S. L. B.) has studied this point in a series of biopsy specimens taken from the site of bony union four weeks after the operation of compression arthrodesis (Charnley and Baker 1952). Here there is a rapid aseptic healing limited to a narrow zone of repair tissue (2-3 millimetres wide in the specimen from which Figure 14 was taken). Figure 14 shows the neighbouring fatty tissue with venous capillaries as large and as numerous as those in our case of disappearing bone shown in Figure 13. In the region from which Figure 13 was taken the diameters of the vessels ranged from 65 to $105 \mu$; in that from which Figure 14 was taken the range was 84 to $126 \mu$; and in Figures 2-D, 7 and 9 in Gorham and Stout's paper the range was 75 to $100 \mu$. The only difference noticeable between the vessels seen in Figure 13 and those in Figure 14 is the slightly thicker walls in the former. (This slight difference is probably real but differences in section thickness can produce such an effect.)

At some sites from which the bone had disappeared Gorham and Stout described and illustrated what appeared to be a network of intercommunicating empty vascular spaces lying between the collagen bundles. In Gorham and Stout's Figures 3-C and 6-C, which showed the appearance best, the bundles were for the most part cut transversely. Our Figure 16 shows what appear to be the same spaces with the collagen bundles cut mainly longitudinally. Thin-walled spaces cannot, of course, exist empty in the body, and they must have been distended with some fluid, presumably venous blood which filled the waste space remaining after removal of the bone. The process would be a gradual one, and the venous capillaries or sinusoids would enlarge to fill the vacant space.

Comments-The vascular changes in our case and in most of those discussed by Gorham and Stout have not the features of a neoplastic process. Though the term " haemangiomatosis" implies a neoplastic proliferation of blood vessels, Gorham and Stout evidently did not regard the vascular changes in most of these cases as neoplastic. The occurrence of these enlarged blood-filled venous capillaries is a non-specific reaction accompanying various kinds of cellular activity in or near bone.

In our case cellular activity with osteoclasis was present on the eroded surface of the remains of the bone. Gorham and Stout (1955) noted in their discussion that " no osteoclasts can be recognised," but in an earlier publication (Gorham, Wright, Shultz and Maxon 1954) the description of the rib biopsy of their first case stated that " histologically much of the cortical and cancellous bone had disappeared and that which remained was surrounded by osteoclasts." It seems highly probable that osteoclasis was the mechanism of bone removal in all the cases and that Gorham and Stout's material would have shown this if their sections had included surfaces where bone removal was in progress at the time of taking the specimen.

Even if it is assumed that the immediate mechanism of bone absorption in these cases was the usual process of osteoclastic erosion found in the removal of normal and pathological bone, there remains to be determined what upsets the normal balance between absorption 
and deposition in the affected region of the skeleton in these cases. Failure of deposition seems an important factor, but the biopsy of our case shows also an increased osteoclasis. Gorham and Stout suggested that the vascular changes are primary and are the cause of the bone absorption. This may be so; but, since increased vascularity is always found with increased cellular activity, both osteoplastic and osteoclastic, the separation of cause and effect seems almost impossible.

As already noted, there was in our biopsy specimen no increased vascularity in the fatty and muscular tissue within a few millimetres of the very vascular bone marrow. This suggests that there was no general vascular congestion (active or passive) of the ron-osseous tissues in the affected region.

\section{SUMMARY}

A case is reported of a woman in whom the bones of one upper limb have been progressively disappearing during at least eleven years. Investigations have thrown no light on etiology or treatment.

\section{REFERENCES}

Boston Medical and Surgical Journal (1838): Case Report: A Boneless Arm, 18, 368. Boston Medical and Surgical Journal (1872): Absorption of the Humerus after Fracture, 87, 245.

Branch, H. E. (1945): Acute Spontaneous Absorption of Bone. Report of a Case involving a Clavicle and a Scapula. Journal of Bone and Joint Surgery, 27706.

Charnley, J., and Baker, S. L. (1952): Compression Arthrodesis of the Knee. A Clinical and Histological Study. Journal of Bone and Joint Surgery, 34-B, 187.

Coley, B. L. (1949): Neoplasms of Bone and Related Conditions. Their etiology, pathogenesis, diagnosis and treatment. New York: Paul B. Hoeber Inc.

Gorham, L. W., and Stout, A. P. (1955): Massive Osteolysis (Acute Spontaneous Absorption of Bone, Phantom Bone, Disappearing Bone: Its Relation to Haemangiomatosis). Journal of Bone and Joint Surgery, 37-A, 985.

Gorham, L. W., Wright, A. W., Shultz, H. H., and Maxon, F. C., Jun. (1954): Disappearing Bones, a Rare Form of Massive Osteolysis. American Journal of Medicine, 17, 674.

Kölliker, A. (1873): Die normale Resorption des Knochengewebes und ihre Bedeutung für die Entstehung der typischen Knochenformen. Leipzig: F. C. W. Vogel.

MaXimow, A. (1927): Bindegewebe und blutbildende Gewebe. In Handbuch der mikroskopischen Anatomie des Menschen. Herausgegeben von W. v. Moellendorff. Band II/1, p. 384. Berlin: J. Springer. 